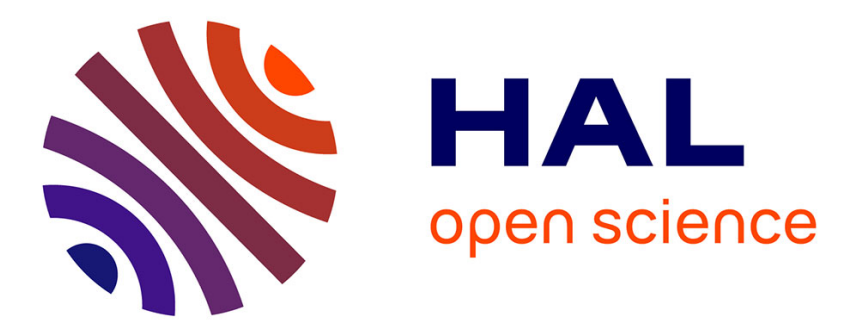

\title{
Numerical study of the influence of Diesel post injection and exhaust gas expansion on the thermal cycle of an automobile engine
}

Ali Hocine, Bernard Desmet, Smaïl Guenoun

\section{To cite this version:}

Ali Hocine, Bernard Desmet, Smaïl Guenoun. Numerical study of the influence of Diesel post injection and exhaust gas expansion on the thermal cycle of an automobile engine. Applied Thermal Engineering, 2010, 30 (14-15), pp.1889. 10.1016/j.applthermaleng.2010.03.033 . hal-00660109

\section{HAL Id: hal-00660109 \\ https://hal.science/hal-00660109}

Submitted on 16 Jan 2012

HAL is a multi-disciplinary open access archive for the deposit and dissemination of scientific research documents, whether they are published or not. The documents may come from teaching and research institutions in France or abroad, or from public or private research centers.
L'archive ouverte pluridisciplinaire HAL, est destinée au dépôt et à la diffusion de documents scientifiques de niveau recherche, publiés ou non, émanant des établissements d'enseignement et de recherche français ou étrangers, des laboratoires publics ou privés. 


\section{Accepted Manuscript}

Title: Numerical study of the influence of Diesel post injection and exhaust gas expansion on the thermal cycle of an automobile engine

Authors: Ali Hocine, Bernard Desmet, Smaïl Guenoun

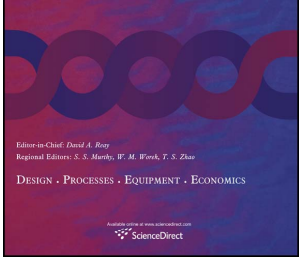

PII:

S1359-4311(10)00237-1

DOI:

10.1016/j.applthermaleng.2010.03.033

Reference: $\quad$ ATE 3125

To appear in: Applied Thermal Engineering

Received Date: 16 October 2009

Revised Date: 9 March 2010

Accepted Date: 29 March 2010

Please cite this article as: A. Hocine, B. Desmet, S. Guenoun. Numerical study of the influence of Diesel post injection and exhaust gas expansion on the thermal cycle of an automobile engine, Applied Thermal Engineering (2010), doi: 10.1016/j.applthermaleng.2010.03.033

This is a PDF file of an unedited manuscript that has been accepted for publication. As a service to our customers we are providing this early version of the manuscript. The manuscript will undergo copyediting, typesetting, and review of the resulting proof before it is published in its final form. Please note that during the production process errors may be discovered which could affect the content, and all legal disclaimers that apply to the journal pertain. 


\title{
Numerical study of the influence of Diesel post injection and exhaust gas expansion on the thermal cycle of an automobile engine
}

\author{
Ali HOCINE a ${ }^{\text {, Bernard DESMET }}{ }^{\text {b }}$, Smaïl GUENOUN ${ }^{\text {a }}$ \\ ${ }^{a}$ Université Paris Ouest - Nanterre La Défense, L.T.I.E - EA 4415, GTE, I.U.T de Ville d'Avray, \\ 50 rue de Sèvres, F - 92410 Ville d'Avray, FRANCE \\ ${ }^{\mathrm{b}}$ Université de Valenciennes et du Hainaut Cambrésis, Laboratoire de Mécanique et Énergétique \\ Le Mont Houy, F - 59313 Valenciennes Cedex 9, FRANCE
}

\begin{abstract}
This study deals with the development of a numerical tool developed to analyze the thermo-management of the heat rejection from the fuel combustion in the case of a four cylinder $2 \mathrm{~L}-110 \mathrm{HP}$ direct injection Diesel engine. It is composed of two main elements: the first one simulates all the phenomena linked to the combustion, the second one is about thermal exchanges in the heart of the engine. We only deal with the first one here.
\end{abstract}

The combustion study is based on two aspects: the consideration of multi injection (the pilot injection, the main injection and the post injection) and the simulation of compressible flows through the exhaust valves.

This model allows us to predict the combustion chamber energy balance (heat fluxes, mechanical work) and the fuel consumption with an experimental tolerance within $3 \%$. Engine tests have been made at the laboratory to validate this result.

Fuel consumption calculation is linked to the accurate estimation of the exhaust gas flow and temperature. The main interest of this method is that it takes into account the sonic blockage at the exhaust valve opening.

This work has also allowed to precise the post injection importance during the engine temperature rise. The increase in thermal rejects is used to accelerate the warm up of the different engine fluids.

Keywords: Diesel Engine, Transient heat transfer, Post injection, Thermomanagement, Compressible flow, Exhaust valve 


\section{Nomenclature}

C

Torque [ N.m ]

$c_{p}$

Specific heat capacity under constant pressure $\left[\mathrm{J} \mathrm{kg}^{-1} \mathrm{~K}^{-1}\right]$

$c_{v}$

Specific heat capacity under constant volume $\left[\mathrm{J} \mathrm{kg}^{-1} \mathrm{~K}^{-1}\right.$ ]

$h$

Enthalpic energy in the combustion chamber [ $\mathrm{J}$ ]

$h_{r}$

Enthalpic energy in the exhaust pipe [ $\mathrm{J}$ ]

$h_{v}$

Enthalpic energy in the valve [ $\mathrm{J}$ ]

$k_{w}$

Wiebe caracteristic constant [ - ]

$k_{w, p o s t}$

Wiebe caracteristic constant for the post combustion [- ]

$L C V$

Fuel Lower Calorific Value [ $\mathrm{J} \mathrm{kg}^{-1}$ ]

$L_{b}$

Connecting rod length [ $\mathrm{m}$ ]

$m$

Mass of the control volume [ $\mathrm{kg}$ ]

$m_{c a r b}$

Fuel mass injected in the control volume during an engine cycle [ $\mathrm{kg}$ ]

$\stackrel{\bullet}{m_{e}}$

Exhaust gas mass flow rate [ $\mathrm{kg} \mathrm{s}^{-1}$ ]

-

$m_{i}$

Intake air mass flow rate $\left[\mathrm{kg} \mathrm{s}^{-1}\right]$

$N$

Rotational speed [ rpm ]

$P$

Fluid pressure of the control volume [ $\mathrm{Pa}$ ]

$P_{r}$

Fluid pressure in the exhaust pipe [ $\mathrm{Pa}$ ]

$P_{v}$

Fluid pressure in the valve [ $\mathrm{Pa}]$

$R_{m}$

Crank beam $[\mathrm{m}]$

$r$

Specific constants of perfect gases $\left[\mathrm{J} \mathrm{kg}^{-1} \mathrm{~K}^{-1}\right.$ ]

$S_{p}$

Area of the piston section $\left[\mathrm{m}^{2}\right]$

$S_{r}$

Area of the pipe section [ $\left.\mathrm{m}^{2}\right]$

$S_{v}$

Area of the valve section [ $\left.\mathrm{m}^{2}\right]$

$T$

Fluid temperature of the control volume, in the combustion chamber [ K ]

$T_{0} \quad$ Temperature of the ambient air [ K ]

$T_{i} \quad$ Temperature of the inlet air [ K ]

$T_{r} \quad$ Fluid temperature in the exhaust pipe [ K ]

$T_{r_{-} \text {enth }} \quad$ Enthalpic gas temperature in the exhaust pipe [ K ] 


$\begin{array}{ll}T_{e} & \text { Temperature of the exhaust gas [ K ] } \\ T_{v} & \text { Fluid temperature in the valve [ K ] } \\ T_{\text {water }} & \text { Water coolant temperature [ K ] } \\ t & \text { Time [ s ] } \\ V & \text { Control volume [ } \mathrm{m}^{3} \text { ] } \\ v & \text { Fluid velocity in the combustion chamber }\left[\mathrm{m} \mathrm{s}^{-1}\right] \\ v_{p} & \text { Piston speed [ } \mathrm{m} \mathrm{s}^{-1} \text { ] } \\ v_{r} & \text { Fluid velocity in the exhaust pipe [ } \mathrm{m} \mathrm{s}^{-1} \text { ] } \\ v_{v} & \text { Fluid velocity in the valve [ } \mathrm{m} \mathrm{s}^{-1} \text { ] } \\ x_{b} & \text { Burnt mass fraction [ - ] } \\ x_{b, \max } & \text { Value of maximum instantaneous burnt mass fraction [ - ] }\end{array}$

\section{$\underline{\text { Greek symbols }}$}

$\begin{array}{ll}\gamma & \text { Specific heat capacities ratio [ - ] } \\ \theta & \left.\text { Crankshaft angle [ }{ }^{\circ} \mathrm{crk}\right] \\ \theta_{1} & \text { Angle of the maximum instantaneous burnt mass fraction [ }{ }^{\circ} \mathrm{crk} \text { ] } \\ \theta_{d} & \text { Combustion duration }\left[{ }^{\circ} \mathrm{crk}\right] \\ \theta_{d, \text { post }} & \text { Combustion duration of the post combustion }\left[{ }^{\circ} \mathrm{crk}\right] \\ \rho & \text { Fluid density in the combustion chamber [ } \mathrm{kg} \mathrm{m}^{-3} \text { ] } \\ \rho_{r} & \text { Fluid density in the exhaust pipe [ } \mathrm{kg} \mathrm{m}^{-3} \text { ] } \\ \rho_{v} & \text { Fluid density in the valve [ } \mathrm{kg} \mathrm{m}{ }^{-3} \text { ] } \\ \Phi_{\text {comb }} & \text { Heat power produced by the combustion [ W ] } \\ \Phi_{\text {wall }} & \text { Heat power exchange with the combustion chamber walls [ W ] } \\ \omega & \text { Rotational speed [ rad s }{ }^{-1} \text { ] }\end{array}$

\section{$\underline{\text { Abbreviations }}$}

$\begin{array}{ll}\text { DPF } & \text { Diesel Particule Filter } \\ \text { ECE } & \text { Urban cycle for the fuel consumption measurement } \\ \text { EUDC } & \text { Extra-urban cycle for the fuel consumption measurement } \\ \text { HP } & \text { HorsePower }\end{array}$


MVEG Motor Vehicle Emissions Group, driving cycle for fuel consumption and homologation

rpm revolution per minute

TDC Top Dead Center

${ }^{\circ}$ crk Degree of crank angle

$\underline{\text { Subscript }}$

main main injection

post post injection 


\section{Introduction}

Facing more and more restrictive European legislations of reducing fuel consumption and pollutants, car manufacturers are working harder and harder to bring new technological evolutions to internal combustion engines. One of the several ways to increase the energy efficiency and to reduce the pollutant emissions is the speed up of the warm up. It is possible thanks to appropriate management of the thermal energy produced by the fuel combustion: we speak about "thermal management". The main objective of this process is the optimization of the heat transfer between the combustion chamber wall and the fluids (water, air-fuel mixture and oil). This approach is only possible with knowledge, anticipation and control of the thermal behaviour of the engine.

The study presented here is about the development of a numerical model allowing us to study, in a transient mode, the heat transfer between the combustion chamber wall and the fluids. It is based on the interface of a thermal model of the engine and a thermodynamic combustion model. The first model [1-2] is a nodal approach of cooling and lubricating systems, the entire metallic engine masses and the exhaust system. The main interest of this work is based in the presentation of the second one, the thermodynamic combustion model.

Some recent studies show that the thermal behaviour of the direct injection Diesel engine depends on influents parameters as, for example, Diesel multiple injections [3], thermal exchange with the cylinder's walls [4] or gas expansion through the exhaust valve [5]. The thermal contacts inside the combustion chamber (valve/valve seat for example) and the friction thermal losses between piston, segments and skirt are also very important [6-9].

In this paper, gas cycle inside the cylinder is simulated taking into account multiple injections and gas flow blockage through the exhaust valve. One of the key objectives of this model is to calculate precisely the instantaneous mass flow rate and the temperature of the exhaust-gas when leaving the combustion chamber.

We mainly focus on this thermodynamic combustion model of the engine although some results of the global model are also presented.

\section{Combustion simulation}

The presented principle of the combustion simulation is to describe the evolution of the thermodynamic gas parameters (temperature, pressure and density) inside the cylinder.

The first thermodynamic principle is applied to a control volume $V$ of fluid delimited by the combustion chamber, whose mass is $m$, temperature is $T$ and pressure is $P$. We do not consider the kinetic energy, the situation potential energy and the viscosity effects with regard to the internal and chemical energies. As a consequence, in the case of a gas obeying the perfect gas equation of state and with heat capacities depending on the temperature, we have

$$
m c_{v} \frac{\mathrm{d} T}{\mathrm{~d} t}=\dot{m}_{i}\left(\int_{T_{0}}^{T_{\mathrm{i}}} c_{p}(T) \mathrm{d} T-\int_{T_{0}}^{T} c_{v}(T) \mathrm{d} T\right)-\dot{m}_{e}\left(\int_{T_{0}}^{T_{e}} c_{p}(T) \mathrm{d} T-\int_{T_{0}}^{T} c_{v}(T) \mathrm{d} T\right)-\Phi_{\text {wall }}+\Phi_{\text {comb }}-\frac{m r T}{V} \frac{\mathrm{d} V}{\mathrm{~d} t}
$$


Thermal exchanges are considered by the instantaneous model of Woschni [10] modified by Hohenberg [11]. The heat power exchange with the combustion chamber $\Phi_{\text {wall }}$ is considered positive when heat is given to the cylinder wall. Heat power produced by the combustion $\Phi_{\text {comb }}$ is expressed by

$$
\Phi_{\text {comb }}=m_{c a r b} L C V \frac{\mathrm{d} x_{b}}{\mathrm{~d} t}
$$

The burnt mass fraction $x_{b}$ describes the evolution of the combustion of the injected oil during an entire combustion cycle. In the case of Diesel engines working in partial charge, a double Wiebe law [12] is generally used to simulate the combustion process with consideration of the two phases : the fast combustion, also called pre-mixed combustion, and the controlled combustion corresponding to diffusion combustion. Much research has been done in order to determine the expressions of fuel burnt fraction and of the burnt fraction rate. The latter corresponds to the fuel combustion speed. Let's refer to the work of Dyechenko [13] and Watson [14]. One of the most used expressions is that of Ghojet [15] and Miyamoto [16]

$$
\left(\frac{\mathrm{d} x_{b}}{\mathrm{~d} \theta}\right)_{\text {main }}=\sqrt{e}\left(\frac{\theta}{\theta_{1}}\right) x_{b, \text { max }} e^{-\frac{1}{2}\left(\frac{\theta}{\theta_{1}}\right)^{2}}+6.908\left(1-\theta_{1} \sqrt{e} x_{b, \max }\right) \frac{1+k_{W}}{\theta_{d}}\left(\frac{\theta}{\theta_{d}}\right)^{k_{W}} e^{-6.908\left(\frac{\theta}{\theta_{d}}\right)^{1+k_{W}}}
$$

The crankshaft angles $\theta_{1}$ and $\theta_{d}$ are expressed in degrees from the beginning of the combustion phenomenon.

This expression is appropriate to single injection laws but it is not sufficient to describe multiple injections. Most of multiple injections systems are composed of three consecutive injections per combustion cycle. The first injection called pilot injection, is mainly dedicated to increase the combustion chamber temperature in order to improve the combustion efficiency during the rest of the cycle. It happens pretty early during the cycle and the quantity of fuel concerned is relatively low. As a consequence, the heat release by the pilot injection is not significant for the application envisaged in the present study. The second injection, called main injection, is the most important one because it generates the main part of the combustion heat. The fuel quantity is a lot more important and the angle of the beginning of the injection is more or less coordinated with the TDC, even if it can change if there is or not pilot and/or post injection. The post injection is a technology developed to regenerate the particule filter (DPF). Its main purpose is to make the combustion longer by injecting fuel during the expansion phase in order to obtain exhaust gas hot enough to burn soot stored in the particle filter: it is called DPF regeneration. It occurs more or less early during the cycle depending on the expected gas temperature. The injected fuel quantity depends on the operating point and is intermediate between the fuel quantity injected of the pilot injection and the quantity of the main injection.

In this study, the formulation (3) is not sufficient. Therefore, we use a second simple Wiebe function to simulate the post injection heat release. This leads us to introduce two new parameters $k_{w, p o s t}$ and $\theta_{d, p o s t}$ for the post injection

$$
\left(\frac{\mathrm{d} x_{b}}{\mathrm{~d} \theta}\right)_{\text {post }}=6.908 \frac{1+k_{w, \text { post }}}{\theta_{d, \text { post }}}\left(\frac{\theta}{\theta_{d, \text { post }}}\right)^{k_{w, \text { post }}} e^{-6.908\left(\frac{\theta}{\theta_{d, \text { post }}}\right)^{1+k_{w, \text { poss }}}}
$$


We mainly focus on the calculation of the exhaust temperature. Therefore, the pilot injection is ignored because its influence on the exhaust temperature is negligible.

To sum up, we simultaneously use a double Wiebe function to modelise the injected fuel during pilot and main injections, and a simple Wiebe function to modelise the injected fuel during post injection. Thanks to tests performed with an experimental engine, the 6 parameters used in the Wiebe functions are linked with analytical functions related to the engine speed and torque. These links represent the predictive part of the model: the burnt fraction and the burnt fraction rate are determined without need of the cylinder pressure signal (Fig. 1). The latter is an outcome of the model, recalculated for each engine speed (Fig. 2).

Fig. 3 compares a burnt fraction signal obtained experimentally with one calculated by the combustion model for a low-load operation point (low torque, low engine speed). For this operation point, the pilot combustion is significant when it is compared to the main combustion. Indeed, it represents $25 \%$ of the main combustion. The graph of burnt fuel fraction, represented by the Wiebe function, has a unit integral. As the pilot injection is not considered in the model, the heat release of the main injection is therefore larger. With respect to the main combustion, there is a significant difference between the model's Wiebe function and the burnt fuel fraction calculated from the experimental pressure profile. This difference no longer manifests itself in the case of post-combustion.

In the context of the modelisation of an engine operated in transient conditions, the Wiebe law coefficients are calculated by analytical links determined at stabilised engine speeds. For the Wiebe law parameters, we will consider that the engine speed is quasi steady.

Friction thermal losses between piston, segments and skirt are calculated according to the Benhassaine model [7]. It leads separately to the instantaneous power dissipated by friction for any of each segment and for the skirt.

\section{Exhaust gas properties simulation}

The air flow through the exhaust valve is calculated analytically, according to the theoretical development presented in this study. It takes into account the effects of compressibility following a 1D pseudo steady state approach, including the sonic blockage of the valve and the adiabatic expansion of hot gases immediately after the valve, when the section suddenly increases going from the valve to the manifold.

During its opening phase, the exhaust valve and the manifold are considered as a convergent nozzle (Fig. 4), between sections 'cylinder' and 'valve' and a sudden expansion, between sections 'valve' and 'pipe'. The flow is considered quasi-steady. The pressure in the chamber is calculated with the model described above. The pressure at the end of the manifold is assumed to be equal to the pressure at the inlet of the turbine. The phenomena are then described for the sonic flow and the subsonic one.

\section{Sonic flow case}

When the exhaust valve begins to open, the pressure difference between the cylinder and the exhaust manifold is sufficient to produce sonic blockage in the section of minimum 
area (Mach number equal to 1 in the corresponding section). The gas is considered as ideal. The flow is assumed as isentropic in the convergent nozzle and adiabatic but irreversible in the expansion. The quasi-steady flow equation energy between cylinder and exhaust valve yields to

$$
\frac{v^{2}}{2}+h=\frac{v_{v}^{2}}{2}+h_{v}
$$

Considering that the velocity inside the cylinder is negligible when compared to the velocity through the valve and as the Mach number in the reduced section $S_{v}$ is equal to 1 , the mass flow rate can be expressed by

$$
\frac{\mathrm{d} m}{\mathrm{~d} t}=P S_{v} \sqrt{\frac{\gamma}{r T}}\left(\frac{2}{\gamma+1}\right)^{\frac{\gamma+1}{2(\gamma-1)}}
$$

Applying the flow equation energy between cylinder and the manifold, we obtain

$$
\frac{\frac{\mathrm{d} m}{\mathrm{~d} t} r T_{r}}{P_{r} S_{r}}=\sqrt{2 c_{p}\left(T-T_{r}\right)}
$$

and the temperature at the beginning of the manifold is given by

$$
T_{r}=\frac{-\alpha+\sqrt{\alpha^{2}+4 \alpha T}}{2}
$$

$$
\alpha=\frac{2 T}{\gamma-1}\left(\frac{\frac{P_{r} S_{r}}{P S_{v}}}{\left(\frac{2}{\gamma+1}\right)^{\frac{\gamma+1}{2(\gamma-1)}}}\right)^{2}
$$

\section{Subsonic flow case}

To determine the exhaust gas properties after the exhaust valve, the flow is separated in two parts : the cylinder and the exhaust valve where it is considered as adiabatic reversible, the exhaust valve and the manifold where it is considered as adiabatic but irreversible.

Using the Barré Saint-Venant theorem between the cylinder and the exhaust valve and considering perfect gas assumption, the gas mass flow is calculated with

$$
\frac{\mathrm{d} m}{\mathrm{~d} t}=P S_{v} \sqrt{\frac{2 \gamma}{(\gamma-1) r T}\left[\left(\frac{P_{v}}{P}\right)^{\frac{2}{\gamma}}-\left(\frac{P_{v}}{P}\right)^{\frac{\gamma+1}{\gamma}}\right]}
$$

Between the exhaust valve and the manifold, the adiabatic flow cannot be assumed as reversible. However, the energy equation can be applied and yields to

$$
\frac{v_{v}{ }^{2}}{2}+c_{p} T_{v}=\frac{v_{r}{ }^{2}}{2}+c_{p} T_{r}
$$


The momentum theorem is applied to the adapted control volume, considering the pressure $P_{v}$ as constant in the valve.

$$
\frac{\mathrm{d} m}{\mathrm{~d} t}\left(v_{r}-v_{v}\right)=\left(P_{r}-P_{v}\right) S_{r}
$$

Finally, from mass flow conservation, the density mass expression in the manifold is obtained as the second mass flow expression.

$$
\frac{\mathrm{d} m}{\mathrm{~d} t}=\rho_{r} S_{r} \sqrt{\frac{2 \gamma r}{(\gamma-1)}\left(T-\frac{P_{r}}{\rho_{r} r}\right)} \quad \text { with } \quad \rho_{r}=\rho\left(\frac{P_{v}}{P}\right)^{\frac{1}{\gamma}} \frac{\frac{P_{r}}{P_{v}} \frac{\gamma+1}{\gamma-1}+1}{\frac{S_{r}}{S_{v}}\left(\frac{P_{r}}{P_{v}}-1\right)+\frac{2 \gamma}{\gamma-1}}
$$

As a consequence, to determine the mass flow, we have to solve a nonlinear system composed of equations (9) and (12) related to each flow part. When $P_{v}$ and $\frac{d m}{d t}$ are obtained, the other gas characteristics can easily be calculated.

\section{Intake process}

The flow is considered incompressible conditioned by the piston displacement. During the air intake process, the air pressure is around of the combustion chamber pressure (about 1 to 1.3 bar), so it is not necessary to simulate the compression effects. The mass flow is proportional to the piston speed.

$$
\frac{\mathrm{d} m}{\mathrm{~d} t}=\rho S_{p} v_{p} \quad \text { with } \quad v_{p}=R_{m} \omega\left[\sin (\theta)+\frac{\frac{R_{m}}{L_{b}} \sin (2 \theta)}{2 \sqrt{1-\left(\frac{R_{m}}{L_{b}} \sin (\theta)\right)^{2}}}\right]
$$

\section{Exhaust process}

Fig. 5 shows, for an engine speed of $2500 \mathrm{rpm}$ and an engine torque of 64 N.m, the exhaust air mass flow. In the same Fig. 5, we can observe the evolution of the air mass and of the fuel contained in the chamber as a function of the crankshaft angle. We note the slight increase in mass due to the fuel injection for the main combustion and the post combustion. We underline that the pilot combustion is, for the moment, ignored by the model. However, analyzing the experimental results used for the model correlation, we can notice that the pilot injection represents 15 - $30 \%$ of the main injection. The exhaust process is composed of two phases : at first, from $482^{\circ} \mathrm{crk}$ (valve opening) to $560^{\circ} \mathrm{crk}$, the flow is compressible. For this part of the exhaust gas process, the ratio between combustion chamber pressure and exhaust gas pressure is important (about 60 to 150). The compressibility effects can not be neglected as for the intake process. After this part, from $560^{\circ} \mathrm{crk}$ to $720^{\circ} \mathrm{crk}$ the flow can be considered as incompressible: the mass flow depends on the piston displacement. As a consequence, the cylinder pressure is equal to the downstream pressure, about 1 bar. 
Fig. 6 presents the Mach number evolution calculated at the exhaust valve and the evolution of the gas mass in the chamber as a function of the crankshaft angle. We specifically highlight that a unity Mach number is reached at the throat since the beginning of the valve opening and then, the Mach number decreases to around $560{ }^{\circ} \mathrm{crk}$. At this position, the cylinder pressure and the downstream pressure (turbo amount pressure) are practically equal. Then, the chamber volume decreases. The calculation of the outgoing mass flow is still done with the compressible flow equations detailed previously. A similar model of the phenomena could also have been integrated to calculate the air flow at intake. Indeed, the gaps between the intake pressure and the pressure in the cylinder at the end of the intake are relatively low. Therefore, the effects of compressibility are less obvious than in the case of the calculation of the exhaust gas flow.

To define a mean value of the exhaust temperature, we consider that the gas flow is mono-dimensional. Gases are supposed perfect. The exhaust gas temperature is based on the enthalpy temperature defined by time integration of the instantaneous temperature of the gas going out of the cylinder after the expansion phase.

$$
T_{r_{-} \text {enth }}=\frac{\int_{0}^{4 \pi} \frac{\mathrm{d} m}{\mathrm{~d} \theta} c_{p} T_{r}(\theta) \mathrm{d} \theta}{\int_{0}^{4 \pi} \frac{\mathrm{d} m}{\mathrm{~d} \theta} c_{p} \mathrm{~d} \theta}
$$

The flow and temperature expressions are explained in the previous paragraph, in the case of the opened valve. When the valve is closed, considering the temperature at the end of rejection, the average temperature is then calculated taking into account the lift of the exhaust valve.

Fig. 7 and Fig. 8 show pressure and temperature evolutions in the cylinder and into the exhaust manifold during the exhaust valve opening. The calculation method, considering compressible flow conditions (subsonic and sonic) enables us to determine the gas temperature around the throat and at the beginning of the manifold. We can notice that the throat temperature is slightly different from that of the chamber, whereas the manifold temperature is closer to the gas temperature in the chamber. For this operating test points, the maximum difference between the combustion chamber and the manifold entry are $190{ }^{\circ} \mathrm{C}$ and 2.2 bar.

The combustion model is then linked to the thermal architecture model thanks to the temperature of the combustion chamber walls. This model is entirely independent and able to make predictions. The quantity of injected fuel is calculated in order to reach the mechanical power level specified at the entry of the model and the power lost by friction

Experimental measurements using an engine in the laboratory validated these temperature levels and pressure levels. For the fuel consumption, difference between calculations and measurements is about $3 \%$. 


\section{Thermo-management application to the drivetrain}

The transient engine speed is examined, considering different running parameters with and without post injection, in order to quantify the post injection influence of the drivetrain thermal dynamic on the MVEG normalised cycle.

First of all, the fuel overconsumption generated by the use of post injection can be calculated by the model. The instantaneous consumption, in the case of the basic versions and adding post injection, is presented in Fig. 9. The fuel overconsumption generated by using post injection is of $17 \%$ (Table 1), which remains acceptable compared with the overconsumption created by other equipments like air conditioning or additional heating.

To continue, the post injection influence on the exhaust gas temperature going out of particule filter is determined (Fig. 10). The exhaust gas are relatively cold in basic running: they reach $135^{\circ} \mathrm{C}$ at the end of the second ECE cycle and $250{ }^{\circ} \mathrm{C}$ at the end of MVEG cycle. During post injection, they are hotter : a $110^{\circ} \mathrm{C}$ maximal temperature difference can be reached between basic running and post injection running. The heat release to the exhaust gas can be increase for about 25 to $35 \%$ by using the post injection.

Secondly, when the engine is running with post injection, a water temperature of $70{ }^{\circ} \mathrm{C}$ can be reached 160 seconds earlier than during basic running, which represents a $15 \%$ of the cycle duration (Fig. 11). The heat release to the water coolant can be increase for about 10 to $15 \%$ by using the post injection.

The main result of the model is to show that it is possible to manage the thermal rejection to the water coolant and/or exhaust gas and calculate at the same time the overconsumption.

\section{Conclusion}

A new thermodynamic combustion model has been developed, validated and linked to the thermal architecture of a 2 L-110 HP diesel direct-injection engine. This model allows us to predict the combustion chamber energy behavior and the consumption with an accuracy about 3\%. It is composed of two elements : the consideration of post injection based on two consecutive Wiebe laws (a double one dedicated to the principal injection and a simple one related to post injection) and the modelisation of compressible flows going out of the exhaust valves. The accurate calculation of the exhaust gas flow and temperature is the main point of interest of this method that takes into account the sonic blockage at the exhaust valve opening. It has also allowed to underline the post injection importance during the engine temperature rise. The increase in thermal rejects is used to accelerate different fluid temperature rises.

Considering thermomanagement, post injection remains really interesting: it increases thermal transfers. The energy produced and directed to the exhaust gas is increased, which can be used, for instance, to advance the depollution system start. In the same way, the combustion chamber heating is improved thanks to the increased thermal rejects towards the cooling water. This is particularly efficient when starting from cold, for example. The influence of post injection on thermal rejects is obvious: we underline the interest in using this process to speed up the temperature rise of the drivetrain. 


\section{Acknowledgement}

This study was performed with the Research Department of P.S.A. Peugeot Citroen. The authors thanks all people who worked on this study. 


\section{References}

[1] L. Tomaselli, Reduction of the fuel consumption and the polluants emissions of car's thermal engines by optimisation of the coolant engine circuit, PhD., Poitiers University, France, 2000

[2] A. Hocine, Warming optimisation of a car's thermal engine by heat recovery at exhaust gases with modifications of fuel injection parameters, PhD., Valenciennes University, France, July 2003

[3] R.D. Reitz, W.L. Hardy, An experimental investigation of partially premixed combustion strategies using multiple injections in a heavy-duty diesel engine, SAE 2006-01-0917.

[4] M.F.J. Brunt, K.C. Platts, Calculation of heat release in direct injection diesel engines, SAE 1999-01-0187.

[5] G. Descombes, F. Maroteaux, M. Feidt, Study of the interaction between mechanical energy and heat exchanges applied to IC engines, Applied Thermal Engineering, 23 (16) (2003) 2061-2078.

[6] N. Laraqi, Velocity and relative contact size effect on the thermal constriction resistance in sliding solids, ASME J. Heat Transfer, 119 (1997) 173-177.

[7] M. Benhassaine, Experimental study and simulation of locals and instantaneous frictions at piston / bore, PhD., Lyon University, France, 1992

[8] A. Baïri, J.M. Garcia-de-Maria, N. Laraqi, Effect of thickness and thermal properties of film on the thermal behavior of moving rough interfaces, European Physical Journal - Applied Physics, 26 (1) (2004) 29-34.

[9] N. Laraqi, N. Alilat, J.M. Garcia-de-Maria, A. Baïri, Temperature and division of heat in a pin-on-disc frictional device - Exact analytical solution, Wear, 266 (7-8) (2009) 765-770.

[10] G. Woschni, A universally applicable equation for the instantaneous heat transfer coefficient in the internal combustion engine, Society of Automotive Engineers, paper $n^{\circ} 670931,1967$

[11] G.F. Hohenberg, Advanced approaches for heat transfer calculations, Society of Automotive Engineers, paper $n^{\circ} 790825,1979$

[12] I.I. Wiebe, New insight into engine cycles (in Russian), M. Mashgiz, p. 35

[13] N.Kh. Dyechenko, Determination of main parameters of heat release characteristics during combustion in Diesel engines, LPI Transactions, $n^{\circ} 316$, Energomshinostroyeniye, 1970, p. 54

[14] N. Watson, A combustion correlation for Diesel engine simulation, Society of Automotive Engineers, paper $n^{\circ} 800029,1980$ 
[15] J. Ghojet, Analytical heat release function for DI Diesel engines, $4^{\text {th }}$ Asian-Pacific international symposium on combustion and energy utilisation, 1991

[16] M. Miyamoto, Description and analysis of Diesel engine rate of combustion and performance using Wiebe's functions, Society of Automotive Engineers, paper $\mathrm{n}^{\circ}$ 850107,1985 


\begin{tabular}{|l|cc|cc|cc|}
\cline { 2 - 6 } \multicolumn{1}{c|}{} & $\begin{array}{c}\text { Without } \\
\text { Post } \\
\text { Injection } \\
\text { (ECE) }\end{array}$ & $\begin{array}{c}\text { With Post } \\
\text { Injection } \\
\text { (ECE) }\end{array}$ & $\begin{array}{c}\text { Without } \\
\text { Post } \\
\text { Injection } \\
\text { (EUDC) }\end{array}$ & $\begin{array}{c}\text { With Post } \\
\text { Injection } \\
\text { (EUDC) }\end{array}$ & $\begin{array}{c}\text { Without } \\
\text { Post } \\
\text { Injection } \\
\text { (MVEG) }\end{array}$ & $\begin{array}{c}\text { With Post } \\
\text { Injection } \\
\text { (MVEG) }\end{array}$ \\
\hline $\begin{array}{l}\text { Over consumption } \\
\text { (compare with BASE) }\end{array}$ & --- & $+17 \%$ & --- & $+12 \%$ & --- & $+\mathbf{1 5 \%}$ \\
\hline
\end{tabular}

Tab. 1. Over consumption measured on MVEG cycle $-7^{\circ} \mathrm{C}$ departure, with an without post injection 
Fig. 1. Instantaneous burnt mass fraction and burnt mass fraction rate ; $N=1500 \mathrm{rpm}$ and $C=41 \mathrm{Nm}$ 


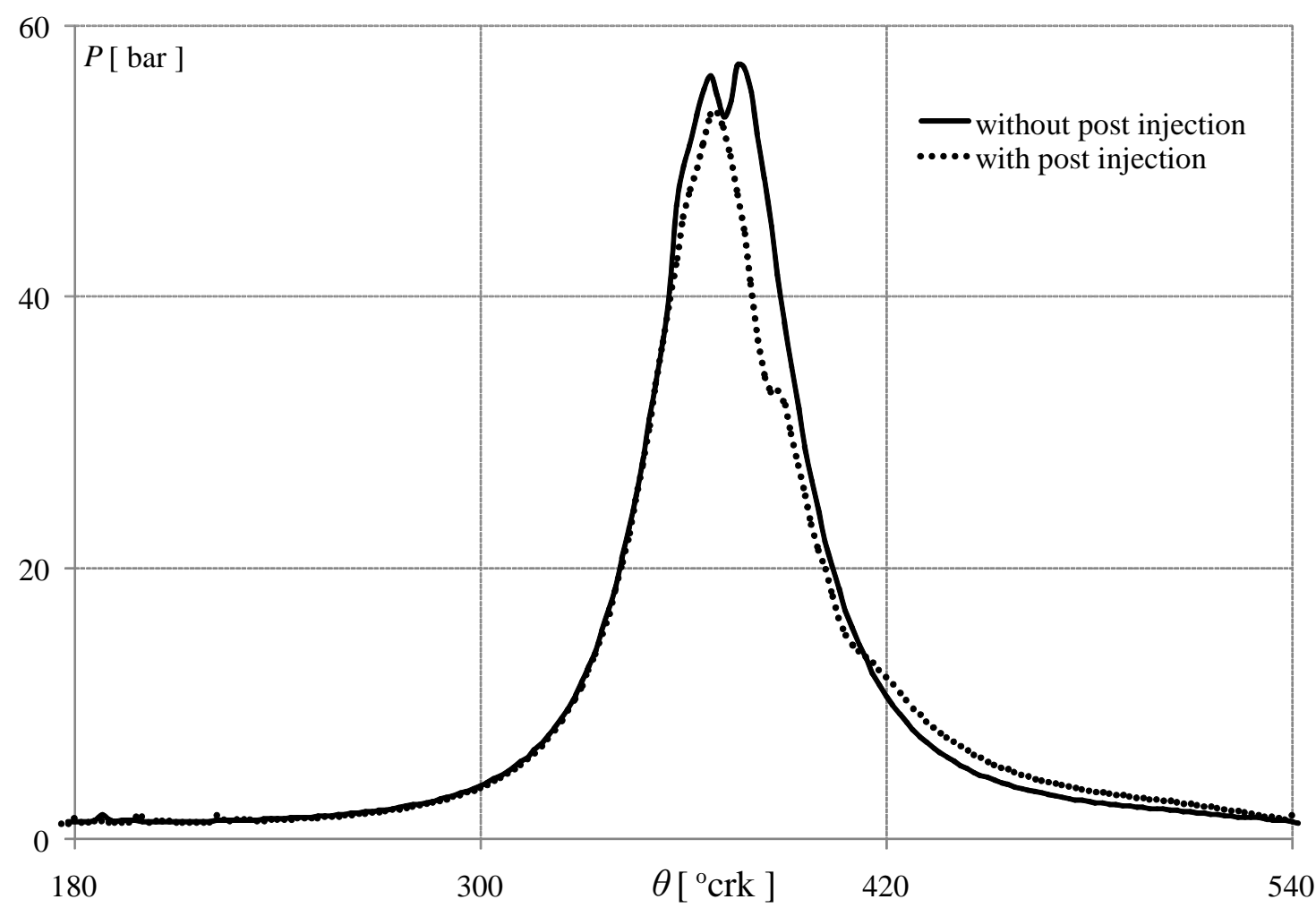

Fig. 2. Cylinder pressure with and without post injection ; $N=1500 \mathrm{rpm}$ and $C=41 \mathrm{Nm}$ 


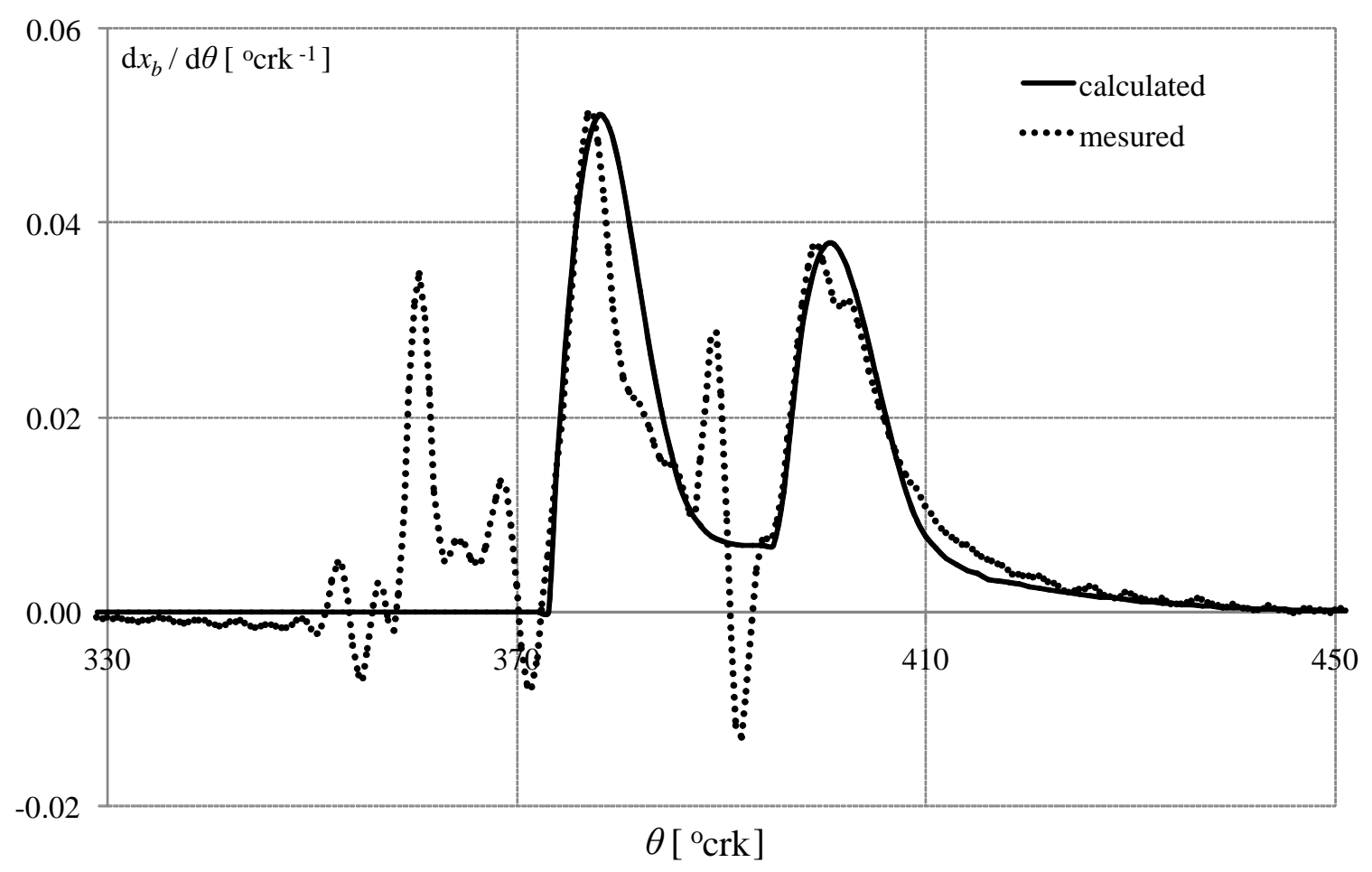

Fig. 3. Instantaneous burnt mass fraction, $N=1500 \mathrm{rpm}$ and $C=41 \mathrm{Nm}$ 


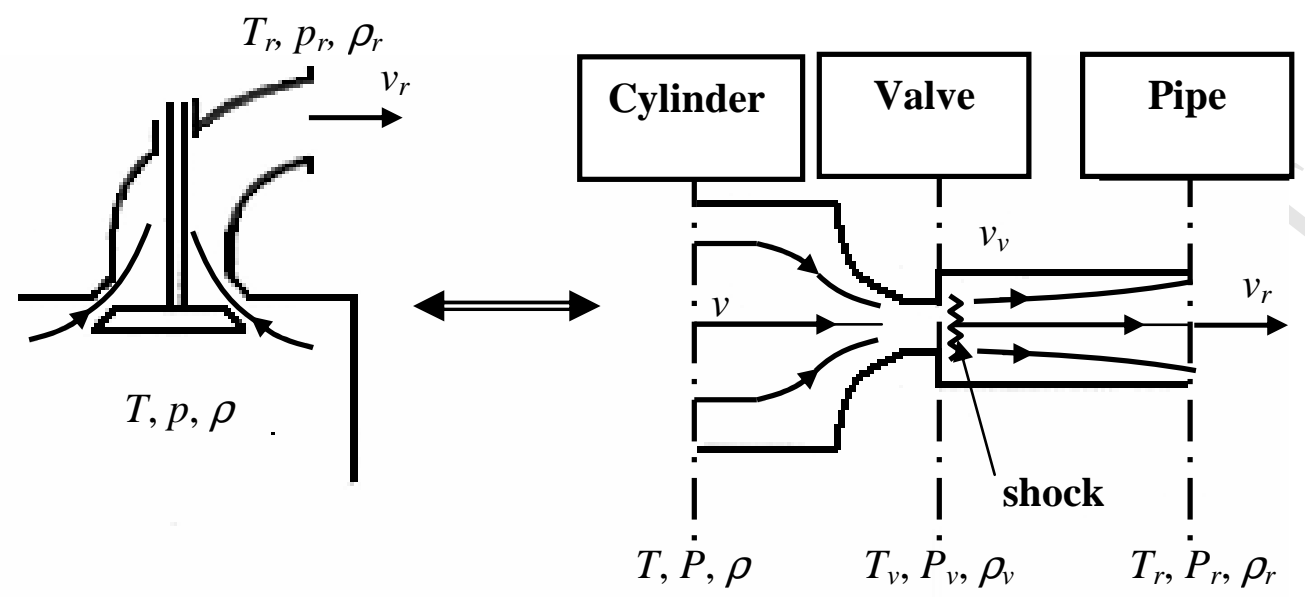

Fig. 4. Model of the flow through the exhaust valve 


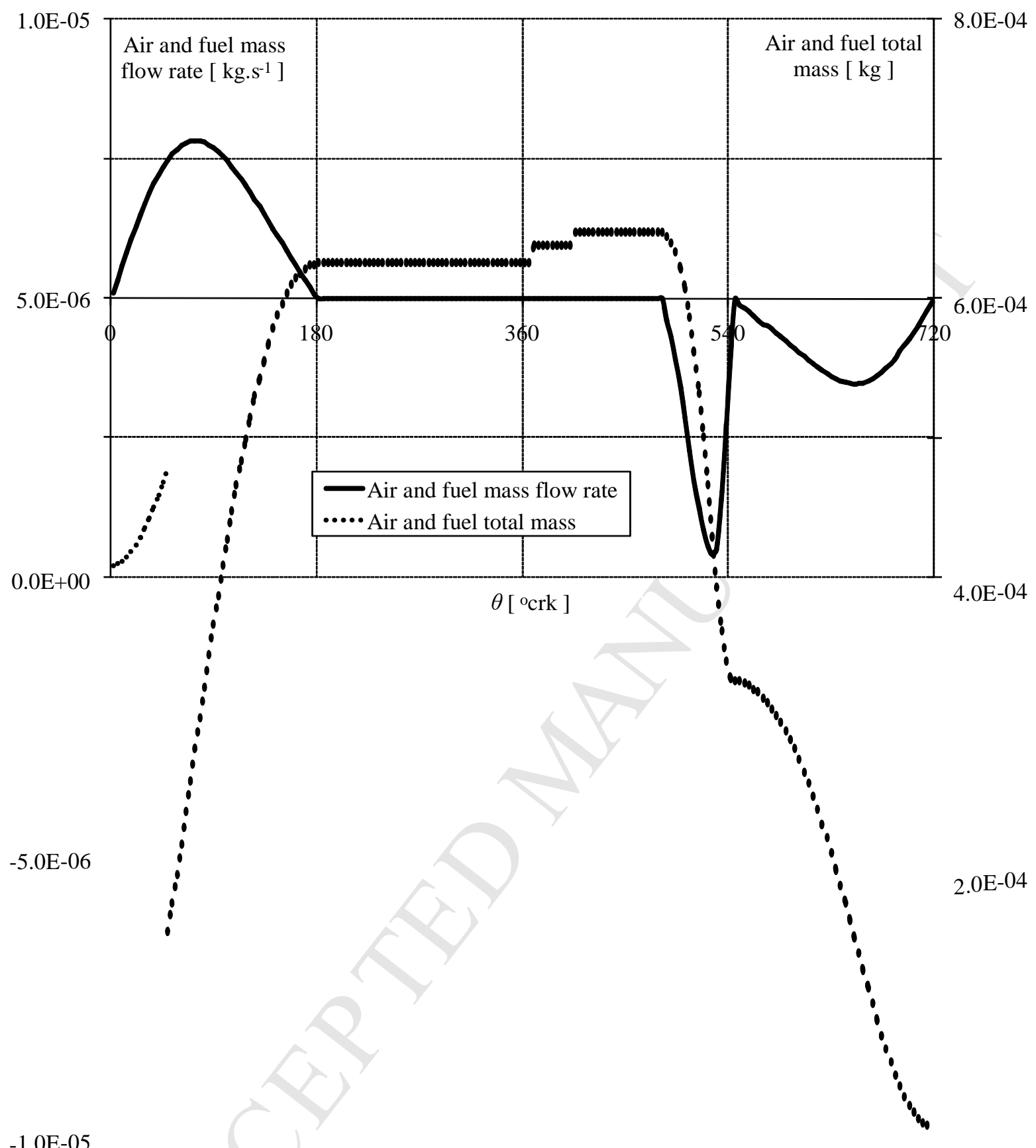


Fig. 5. Air-fuel mass flow rate and mass inside the cylinder, $N=2500 \mathrm{rpm}$ and $C=64 \mathrm{Nm}$ 


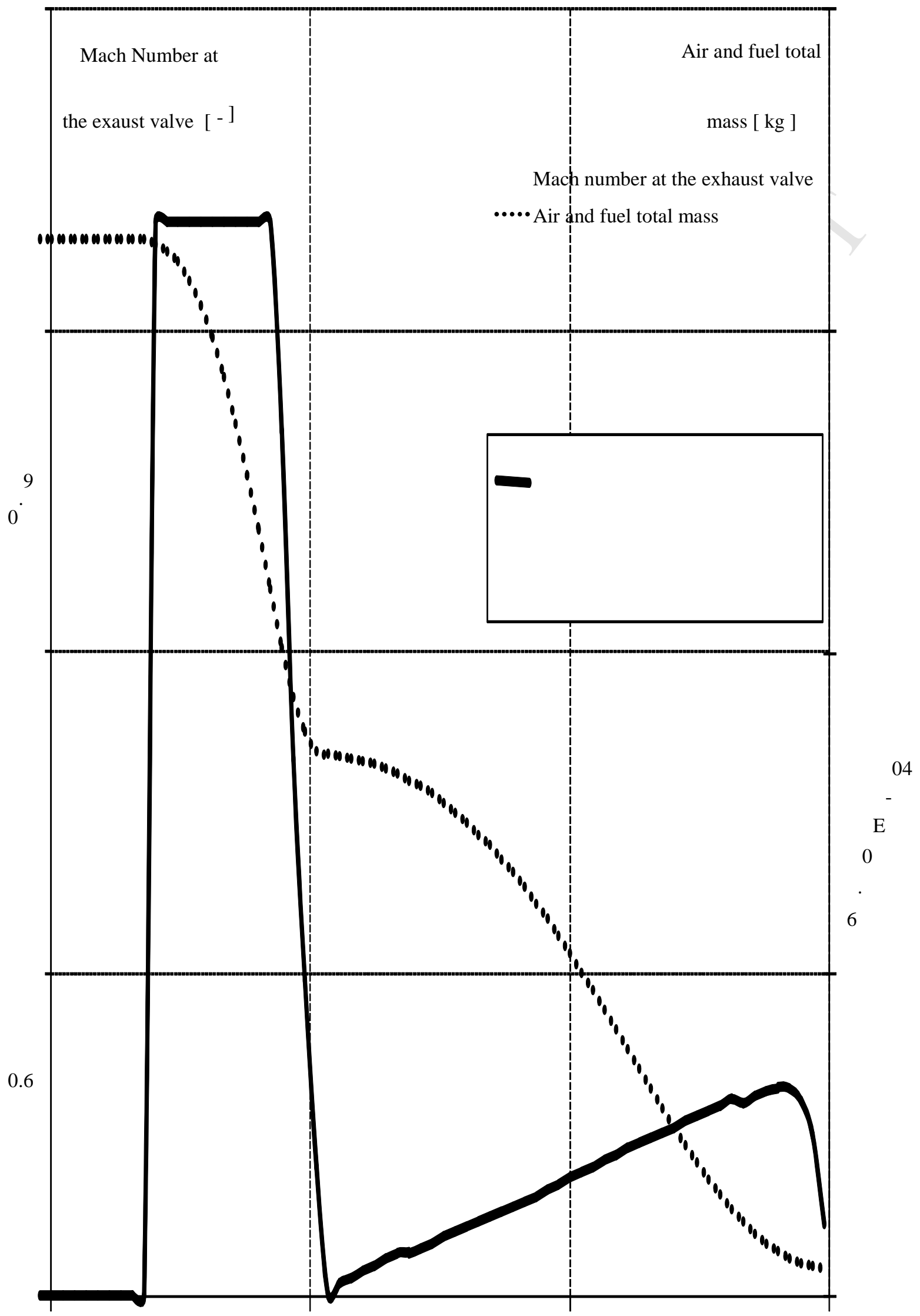


Fig. 6. Mach number at the exhaust valve and air-fuel mass in the combustion chamber, $N=2500 \mathrm{rpm}$ and $C=64 \mathrm{Nm}$ 


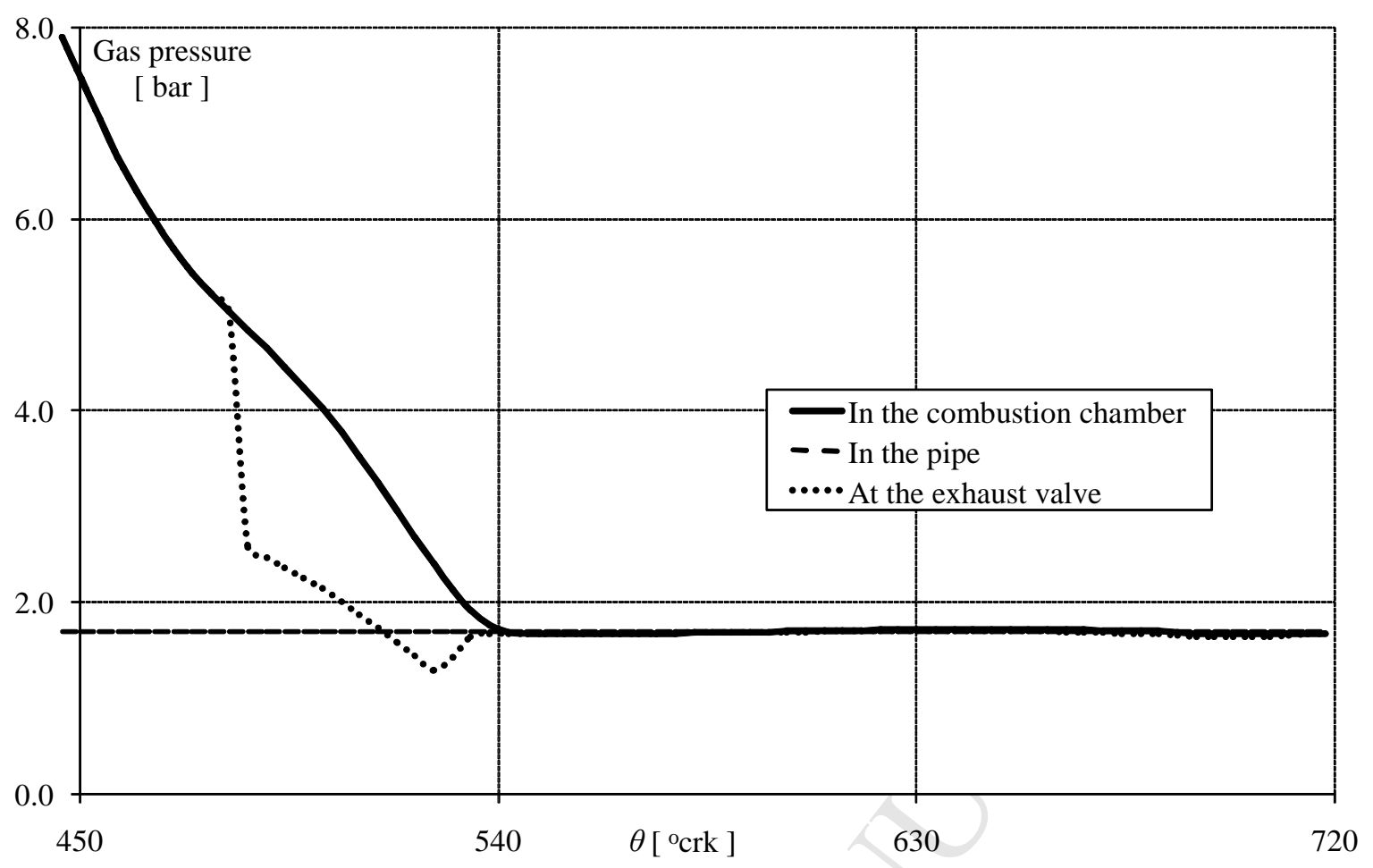

Fig. 7. Gas pressure at different points of the exhaust channel, $N=2500 \mathrm{rpm}$ and $C=64 \mathrm{Nm}$ 


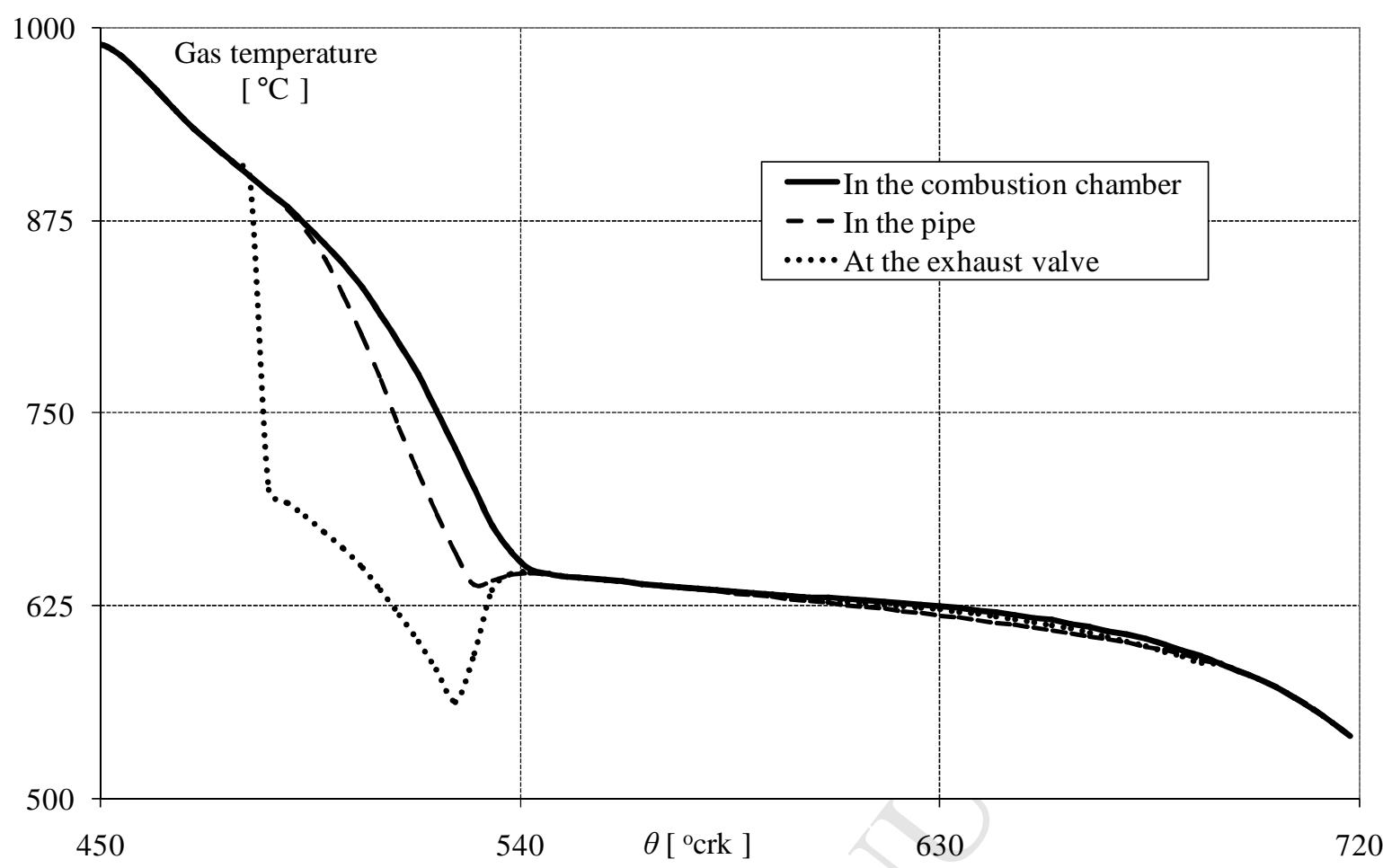

Fig. 8. Gas temperature at different points of the exhaust channel, $N=2500 \mathrm{rpm}$ and $C=64 \mathrm{Nm}$ 


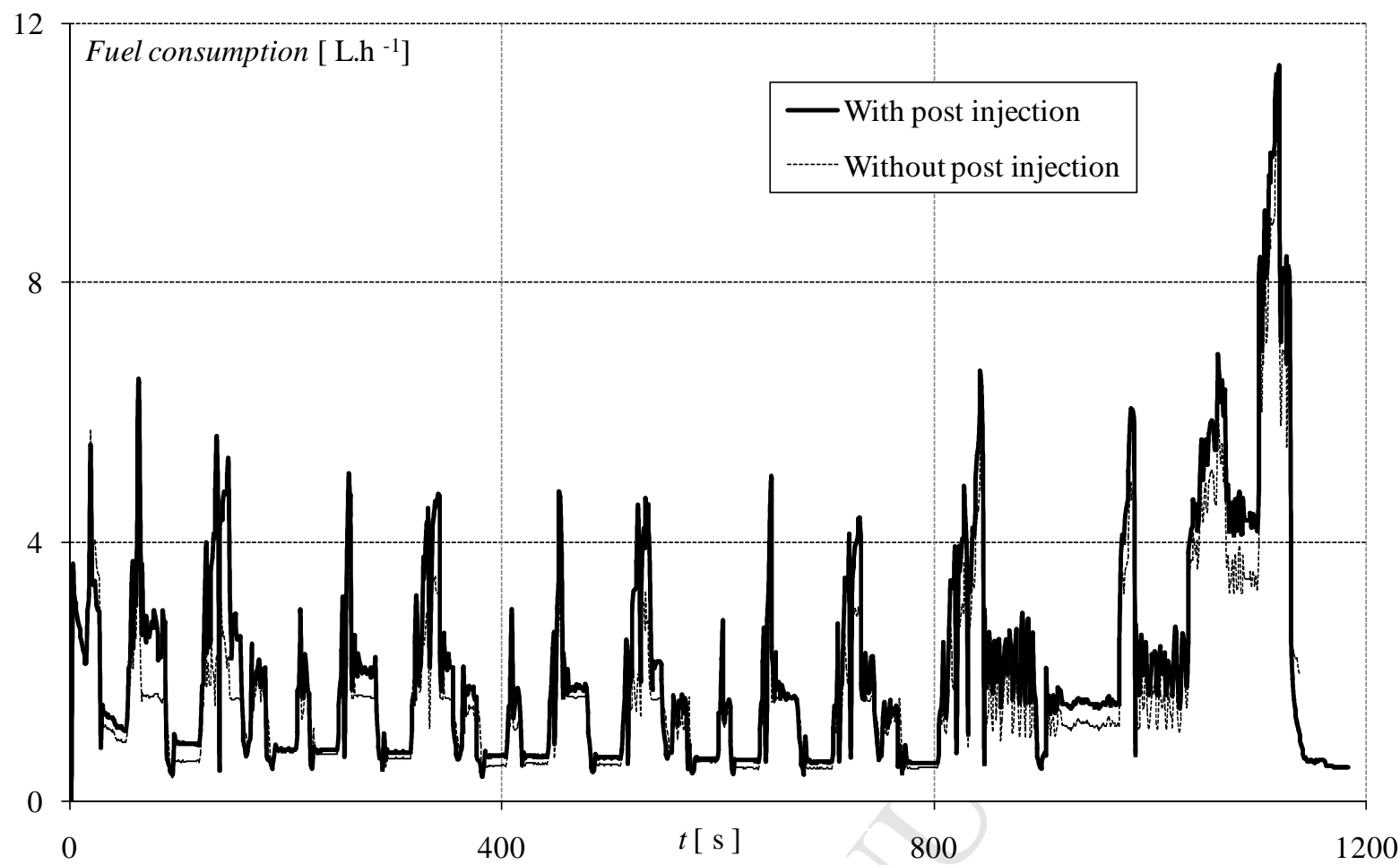

Fig. 9. Instantaneous Diesel consumption on MVEG cycle $-7^{\circ} \mathrm{C}$ departure, with an without post injection 


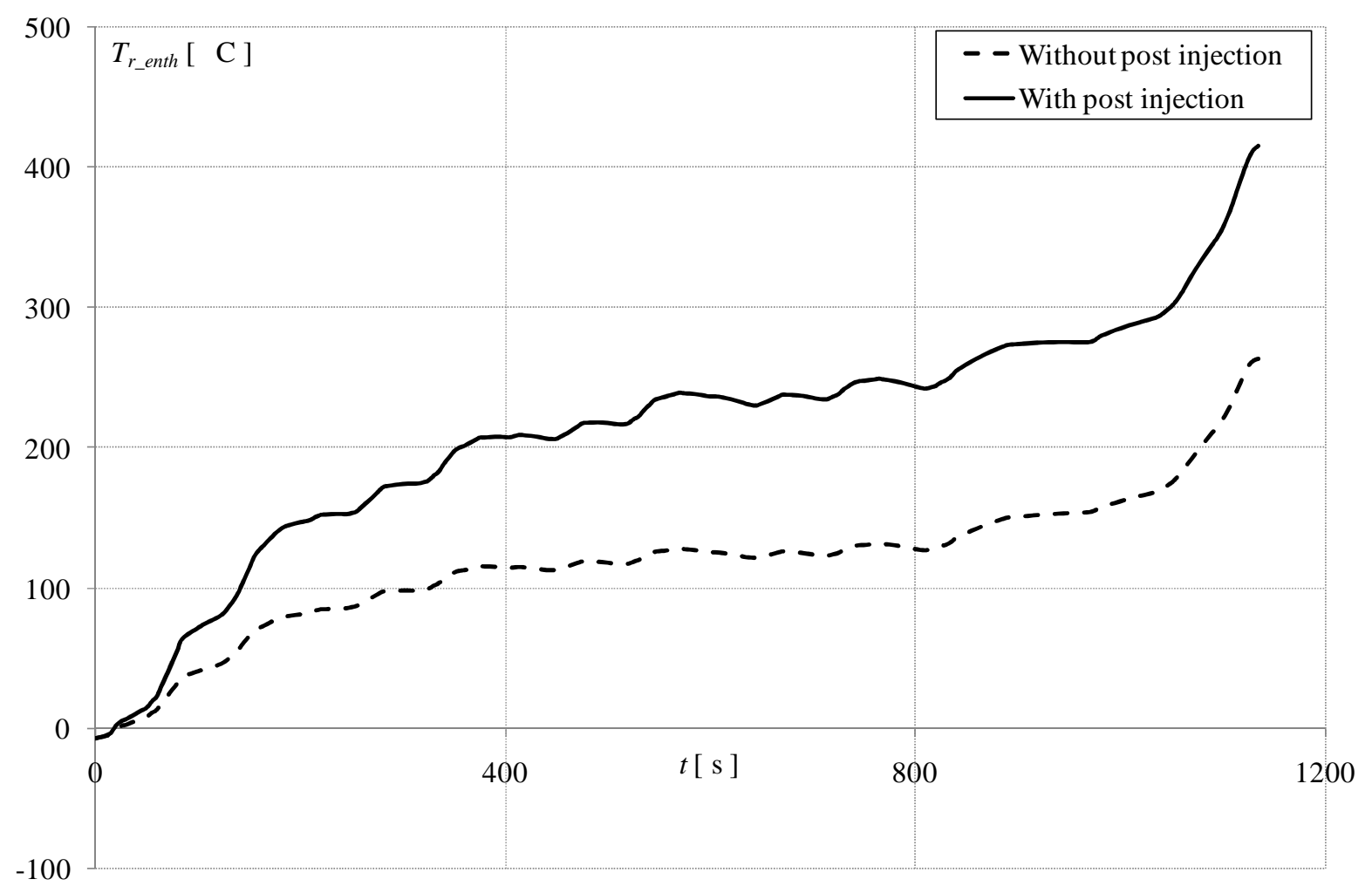

Fig. 10. DPF exhaust gas temperature, on MVEG cycle $-7^{\circ} \mathrm{C}$ departure, with an without post injection 


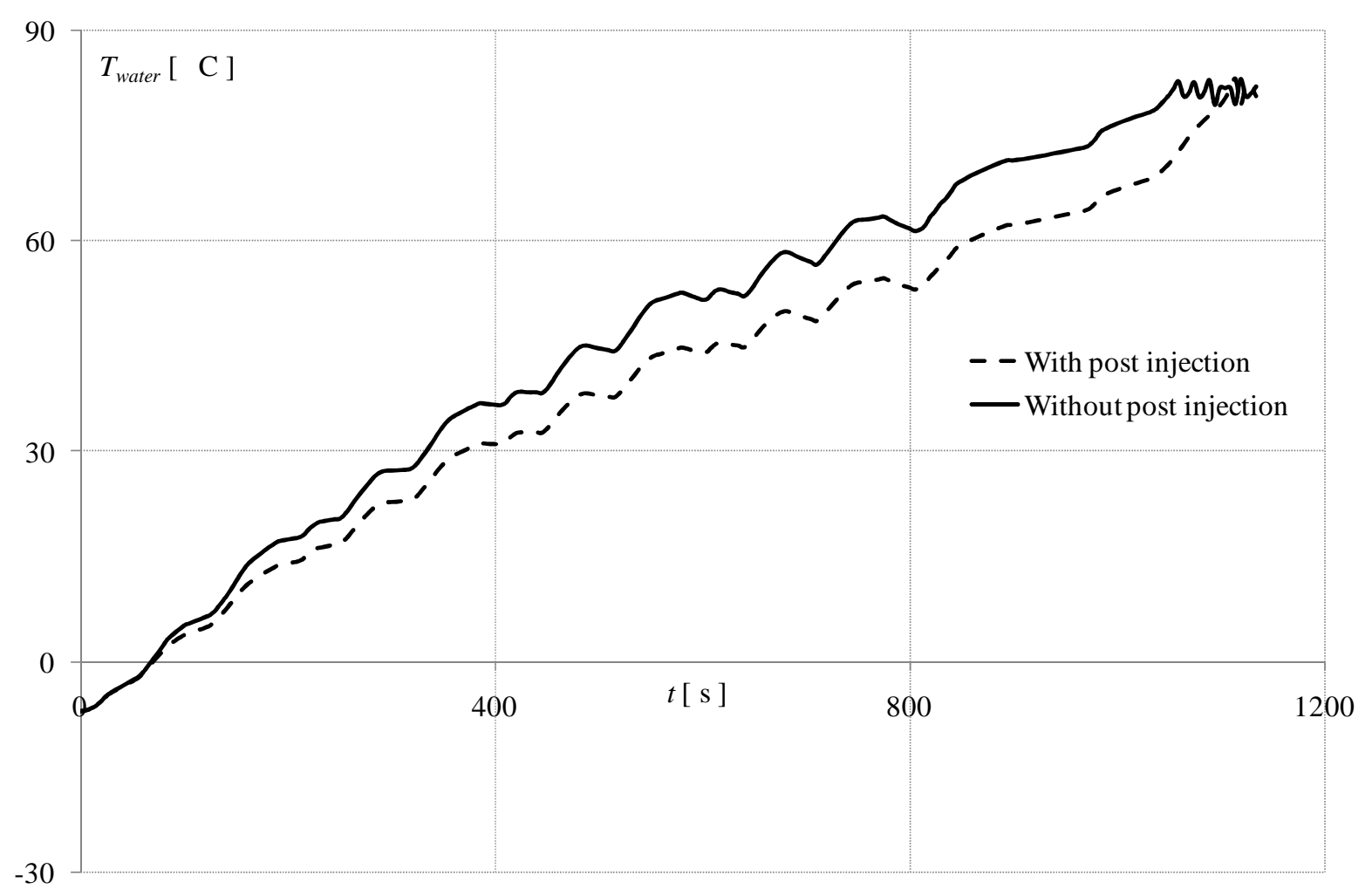

Fig. 11. Water coolant temperature on MVEG cycle $-7^{\circ} \mathrm{C}$ departure, with an without post injection 